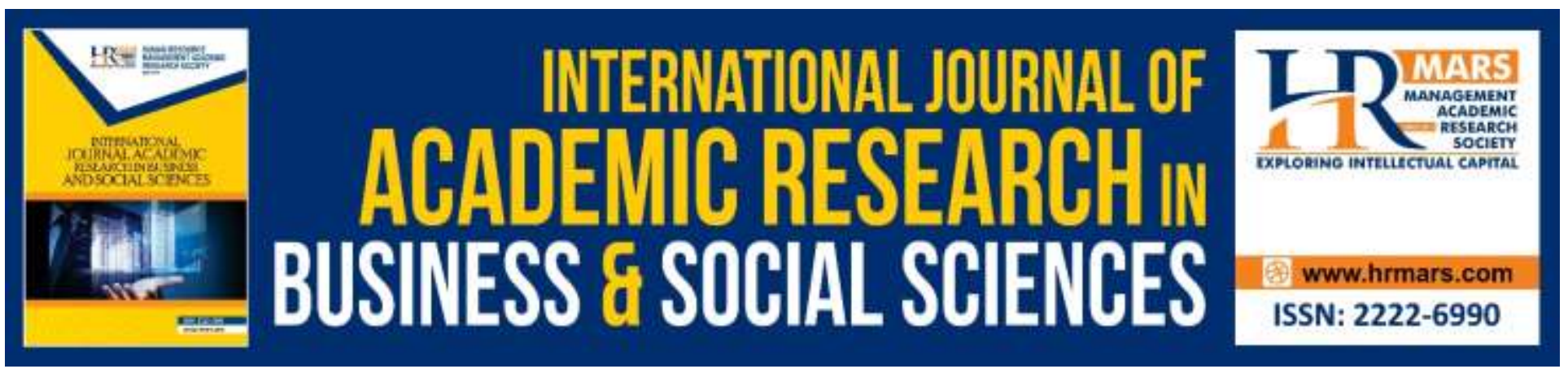

\title{
Leveraging Workforce Diversity to improve Employee Performance in Kenya
}

\section{Wycliffe Mande, Leon Awiti}

To Link this Article: http://dx.doi.org/10.6007/IJARBSS/v9-i7/6123

DOI: $10.6007 /$ IJARBSS/v9-i7/6123

Received: 22 May 2019, Revised: 11 June 2019, Accepted: 04 July 2019

Published Online: 24 July 2019

In-Text Citation: (Mande \& Awiti, 2019)

To Cite this Article: Mande, W., \& Awiti, L. (2019). Leveraging Workforce Diversity to improve Employee Performance in Kenya. International Journal of Academic Research in Business and Social Sciences, 9(7), 339-351.

\section{Copyright: (C) 2019 The Author(s)}

Published by Human Resource Management Academic Research Society (www.hrmars.com)

This article is published under the Creative Commons Attribution (CC BY 4.0) license. Anyone may reproduce, distribute, translate and create derivative works of this article (for both commercial and non-commercial purposes), subject to full attribution to the original publication and authors. The full terms of this license may be seen at: http://creativecommons.org/licences/by/4.0/legalcode

Vol. 9, No. 7, 2019, Pg. 339 - 351

http://hrmars.com/index.php/pages/detail/IJARBSS

JOURNAL HOMEPAGE

Full Terms \& Conditions of access and use can be found at http://hrmars.com/index.php/pages/detail/publication-ethics 


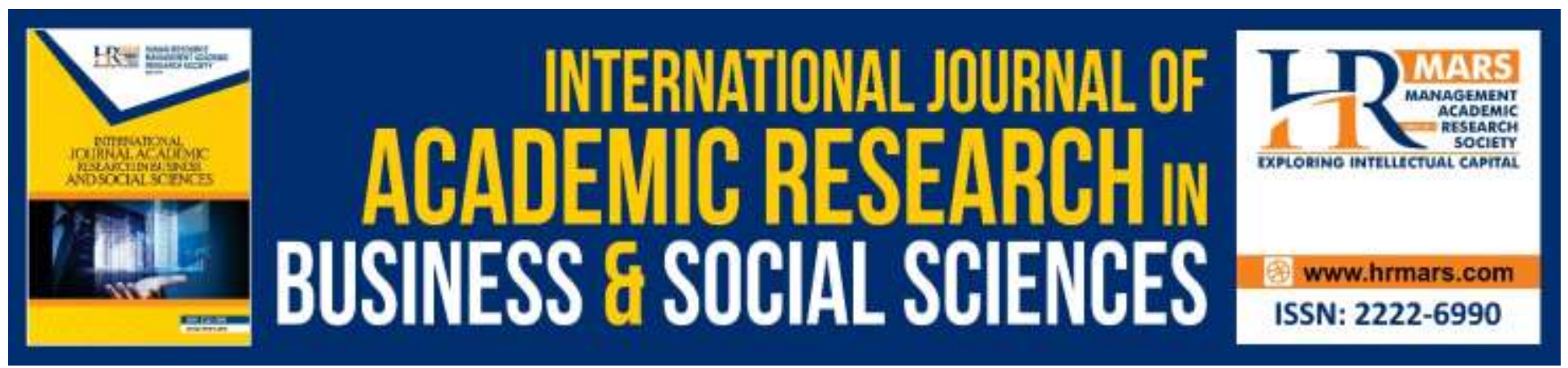

\title{
Leveraging Workforce Diversity to improve Employee Performance in Kenya
}

\author{
Wycliffe Mande \\ Human Resource, Research and Learning Practitioner, Kenya. \\ Email: cliffmande@yahoo.com \\ Leon Awiti, Ph.D. \\ Monitoring, Research, Evaluation and Learning Practitioner, Kenya. \\ Email: awitileon@gmail.com
}

\begin{abstract}
Globalization of business and unprecedented movement of labour across borders have created organizations that comprise a mixture of people from many different cultures, age, gender, ethnic origins and education backgrounds. Managing an organization with a diverse workforce creates challenges in terms of management practices and leadership styles, due to the differing viewpoints it elicits. Overall benefits and challenges of a diverse workforce organization can be closely related to how effective it is managed. This is one of the reasons why diverse workforce is a pressing managerial issue and therefore the basis in which this study was conceived. The objective of this study was to determine the relationship between workforce diversity and employee performance in public universities in Kenya. The study was guided by positivism research philosophy and descriptive survey research design and correlational research design were adopted. The target population included the chairpersons of departments of the public universities in Kenya. Correlation and regression analysis established a statistically significant positive relationship between workforce diversity variables and employee performance. The conclusion drawn from the study findings is that age diversity, gender diversity, ethnic diversity and education background diversity influence employee performance positively and majority of the employees are positive about workforce diversity practices in public universities. The study recommended that the management should continue to uphold its workforce diversity policies and practices in order to increase the benefits of workforce diversity.

Keywords: Workforce Diversity, Employee Performance, Public Universities, Human Resource Management.
\end{abstract}




\section{Introduction}

\section{Workforce Diversity}

Loden and Rosener (1991) define workforce diversity as that which differentiates one group of people from another along primary and secondary dimensions. Primary dimensionsof diversity, those exerting primary influences on our identities, are gender, ethnicity, race, sexual orientation, age and mental or physical abilities and characteristics. They claim that primary dimensions shape our basic self-image as well as our fundamental world views and have the most impact on groups in the workplace and society. Secondary dimensionsof diversity on the other hand are less visible, exert a more variable influence on personal identity and add a more subtle richness to the primary dimensions of diversity. They include: educational background, geographic location, religion, first language, family status, work style, work experience, military experience, organizational role and level, income and communication style. The secondary dimensions impact our self-esteem and selfdefinition (Loden and Rosener, 1991).

Carrell (2006) comments that although workforce diversity has become a reality in organizations today as predicted by Workforce 2000 in a 1987 report by the Hudson Institute, the ways that organizations define and manage workforce diversity are still evolving. The increasing trend of workforce diversity along racial, ethnic and gender lines, as well as an increasing percentage of the workforce that is below the age of 30 and over the age 55 have several implications for human resource professionals, employees and company in general. This arises out of the prejudices that may persist, cultural insensitivity and language differences, increasing numbers of women in the workforce and the aging of the workforce. Academicians and practitioners have sought to understand the impact of diversity and its management on organizational effectiveness.

Managing diversity in the workplace therefore should be a part of the culture of the entire organization (Alder, 2005).Diversity management practices therefore enhance productivity, effectiveness, and sustained competitiveness. Organizations that promote and achieve a diverse workplace will attract and retain quality employees and increase customer loyalty (Alserhan, Forstenlechner and Al-Nakeeb, 2010). Human resource diversity management strategies have broadened beyond affirmative action and equal employment opportunity staffing efforts. Equal employment opportunity starts externally and is enforced through legislation, whereas workforce diversity management starts internally, through the efforts to create an atmosphere of equality and a fully inclusive organizational culture at work (Gordon, 1995). The concept of workforce diversity management has its origin in business management, and it describes the heterogeneity of the employees and identifies different ways to take advantage of it for the benefit of everyone involved and the success of the organization (Cox, 2001).

\section{Objective of the Study}

The objective of this study was to determine the relationship between workforce diversity and employee performance in public universities in Kenya.

\section{Literature Review}

Previous research on workforce diversity suggests that diversity can be either detrimental or beneficial for employee performance. For instance, employee diversity is positively associated with 
creativity and problem-solving skills and negatively related with cohesiveness and cooperation (Erasmus, 2007). Good work force diversity practices in the area of human resources are believed to enhance both employee and organizational performance. Furthermore, employee diversity allows increased creativity, a wider range of perspectives, better problem definition, more alternatives and better solutions. It is also argued that with decreasing homogeneity in the workforce, it has become crucial for organizations to develop equal opportunities and diversity management policies to maintain the skills of employees with diverse backgrounds in order to protect their competitive position in the market place (Kochan et al., 2003).

Ellis and Sonnenfield (1994) argue that there is a relationship between a positive diversity climate, job satisfaction, and commitment to the organization. Proper diversity management can increase an employee's self-esteem and feeling of no belongingness to the organization especially, if the employee is from a minority group. Although an increasing number of organizations are attempting to enhance inclusiveness of underrepresented individuals through proactive efforts to manage their diversity, they may only gain from diversity through proper management and adjustment. To effectively manage diversity, an organization must value diversity; it must have diversity, and it must change the organization to accommodate diversity and make it an integral part of the organization (Gilbert et al., 1999). Good workforce diversity practices in the area of human resources are believed to enhance employee and organizational performance (Hall and Parker, 1993). Diversity brings the value of different employee perspectives and varied types of contribution especially when organizational members increasingly reflect the diverse custom base of the organization. This provides a way in which organizations can understand, and therefore meet, their customer needs. In addition, Carrel (2005) say that for an organization to succeed, its strategies must consist of managing change, establishment of appropriate diversity management policies and procedures and target diversity related competencies. The desired outcomes of diversity include attracting and developing the best employees which should give the organization a competitive edge to generate greater profits that support job security. Due to the fact that employees can understand how these outcomes are desirable, they will support the organization's efforts at managing diversity and embrace a culture that supports diversity (Carrel, 2006).

On the other hand, workforce diversity generates conflicts between employees (Magoshi and Chang, 2009). Conflict occurs due to differences of perception, ideas, behaviors, interest, attitudes, religious differences, political differences and unjustified distribution of resources. Conflict is not always negative and does not always create hostilities. It very much depends on how the conflict is handled. If handled properly, it can become a very rich source of development. When corporate managers ignore the conflicts between co-workers, this will result in clashes amongst them. In turn, these clashes will be converted into personal and emotional conflict in the long run and therefore damages the organizational culture, worker morale, and overall organizational performance (Magoshi and Chang, 2009).

\section{Theoretical Framework}

Diversity theorists have recently turned to the well-established field of social psychology for insights into how diversity affects individuals and groups in organizations. Social psychologists have examined the processes involved with social identity and intergroup relations and diversity scholars recognized 
that this research tradition can provide a solid background for emerging theories on workplace diversity. Organizational researchers often refer to inborn human characteristics as dimensions of diversity, or social category diversity. The theoretical foundations for primary dimensions of diversity include the self-categorization theory (Turner, 1982), the social identity theory (Tajfel, 1978), the similarity paradigm theory (Thatcher, 1999), and the racial identity theory (Jehn, 1999). These theories describe how people react to observable demographic characteristics. The primary dimensions of diversity shape people's perception and behavior without regard to work-task relevance. According to O'Flynn, Ricciotti, Nicholas, Lau, Sammaritino and Fisher (2001) the three most commonly used theories of diversity are the social categorization theory, the similarity attraction paradigm and the informational diversity and decision making perspective. These theories according to the researchers all produce inconsistent and contradictory results.

\section{Research Methodology}

Descriptive survey research design and correlational research design were adopted for this study. Descriptive research studies are studies which are concerned with quantitatively describing the characteristics of a particular individual or characteristics of a group (Kothari, 2009). Mugenda and Mugenda (2003), on the other hand define descriptive research as a process of collecting data in order to test hypothesis or to answer questions concerning the current status of the subject of study. Sekaran (2008) also contends that a descriptive study is undertaken in order to ascertain and be able to describe the characteristics of the variables of interest in a situation. Correlational design established the existence of a relationship or interdependence between two or more aspects of the variables. Moreover, the study used a portion of the population, which is public universities in Western Kenya region, from which the findings were later generalized back to the population. By their very nature, public Universities in Western Kenya region share similar contextual backgrounds with their counterparts in other parts of Kenya. They enjoy same policy regime from the Republic of Kenya; are financed and facilitated by the same government. These designs were used by Sang (2010) and it enabled him answer research questions, test hypotheses and draw plausible conclusions in relation to outsourcing practices in Kenyan Universities.

The instrument for primary data collection in this research was a numerical five point Likert scale questionnaire and it applied to the 120 sampled respondents. Questionnaires are effective instrument of data collection because responses gathered are in a standardized way, so questionnaires are more objective, relatively quick to collect information and potentially information can be collected from a large portion of a group. The instrument also eliminates biases and undue pressure on the respondents (Mellenbergh, 2008). The questionnaire method was selected as it allowed the researcher to collect data systematically and address the research issues in the standardized and economical way. A closed ended questionnaire was developed and used during primary data collection phase to gather information from the chairpersons of departments of the respective universities by the researcher. The research instrument was developed based on the constructs identified in the conceptual framework. 
INTERNATIONAL JOURNAL OF ACADEMIC RESEARCH IN BUSINESS AND SOCIAL SCIENCES

Vol. 9, No. 7, July, 2019, E-ISSN: 2222-6990 @ 2019 HRMARS

\section{Findings and Discussions}

\section{Questionnaire Return Rate}

A total of 120 questionnaires were distributed to the chairpersons of departments. The unit of analysis consisted of four public universities namely: Masinde Muliro University of Science and Technology, Maseno University, Jaramogi Oginga Odinga University of Science and Technology and Kisii University. The respondents who filled and returned usable questionnaires were 93 making a return rate of $78 \%$. The $22 \%$ of the respondents failed to fill the questionnaires even after several follow up. According to Mugenda and Mugenda (2003), a return rate of $50 \%$ is adequate for analysis and reporting; a rate of $60 \%$ is good and a return rate of $70 \%$ and over is excellent. This meant that the return rate of $78 \%$ was excellent and therefore enough for the study to proceed to the data analysis, presentation, interpretation and discussion.

\section{Normality Test}

Normality tests of the variables was conducted for inferential analysis to be done such as correlation, regression or related linear techniques, the variables should have a normal distribution. In case the variables are not normally distributed, then normality has to be sought for before proceeding with any further analysis. Kolmogorov- Smirnov and Shapiro Wilk test was also used to test the normality of all the variables. They compare the scores in the samples and check whether they have the same mean or standard deviation. The Q$Q$ plot is an excellent way of observing whether data deviate from normal. The $Q-Q$ plot normality tests showed that the data on all the variables: Age Diversity, Gender Diversity, Ethnic Diversity, Education Background diversity and Employee Performance were normally distributed. The results are shown in the table below:

Table 4.1: Kolmogorov-Smirnov and Shapiro-Wilk Test

\begin{tabular}{lccc}
\hline & \multicolumn{3}{c}{ Kolmogorov- Smirnov } \\
& Statistic & Df & Sig. \\
\hline Age Diversity & 0.176 & 93 & 0.000 \\
Gender Diversity & 0.192 & 93 & 0.000 \\
Ethnic Diversity & 0.168 & 93 & 0.000 \\
Education Background Diversity & 0.115 & 93 & 0.004 \\
Employee Performance & 0.203 & 93 & 0.000 \\
\hline
\end{tabular}

The Kolmogorov- Smirnov test showed that the data was normally distributed in all the study variables, the $p$ - values are $<0.05, C L=95 \%$.

\section{Independent Errors Test}

One assumption of linear regression is that the error terms are independent. A common violation of this assumption occurs when each error term is related to its immediate predecessor. This is mostly likely to occur when the data points are observed in some sort of meaningful time sequence. The Durbin- Watson statistic was used for test independent error test and results are shown in table 4.2 below. 
INTERNATIONAL JOURNAL OF ACADEMIC RESEARCH IN BUSINESS AND SOCIAL SCIENCES

Vol. 9, No. 7, July, 2019, E-ISSN: 2222-6990 @ 2019 HRMARS

Table 4.2 Independent Errors Test

Std. Error of the Estimate

3.82141
Durbin-Watson

1.717

The Durbin-Watson value is $=1.617<2$, indicated that the residuals are not correlated and therefore the data met the conditions for linear regression analysis.

\section{Collinearity Statistics}

Collinearity is a special case when two or more variables are exactly related, this means the regression coefficients are not uniquely determined. In turn it hurts the inter-pretability of the model as the regression coefficients are not unique and have influences from other features. When predictor variables in the same regression model are correlated, they cannot independently predict the value of the dependent variable and in turn it reduces their statistical significance (Berry, 2010). A collinearity test was done and results are shown in table 4.3 below.

\section{Table 4.3 Collinearity Statistics}

\begin{tabular}{|l|r|c|}
\hline \multirow{2}{*}{ Model } & \multicolumn{2}{|c|}{ Collinearity Statistics } \\
\cline { 2 - 3 } & Tolerance & VIF \\
\hline Age Diversity & 0.429 & 2.330 \\
Gender Diversity & 0.454 & 2.202 \\
Ethnic Diversity & 0.823 & 1.214 \\
Education & 0.500 & 2.000 \\
Background & & \\
Diversity & & \\
\hline
\end{tabular}

a. Dependent Variable: Employee Performance

The analysis of tolerance and VIF values showed that there was no problem of multicollinearity, all the tolerance values were $<1$ while the VIF values were $<10$. 
INTERNATIONAL JOURNAL OF ACADEMIC RESEARCH IN BUSINESS AND SOCIAL SCIENCES Vol. 9, No. 7, July, 2019, E-ISSN: 2222-6990 @ 2019 HRMARS

\section{Correlation Analysis of Workforce Diversity and Employee Performance in Public Universities}

Pearson correlation coefficient is a measure of linear association between two variables. Values of the correlation coefficient are always between -1 and +1 . A correlation coefficient of +1 indicates that two variables are perfectly related in a positive linear sense whereas a correlation coefficient of -1 indicates that two variables are perfectly related in a negative linear sense. On the other hand, a correlation coefficient of 0 indicate that there is no linear relationship between the two variables (Kothari, 2009). The study used Spearman's ranking and the correlation strengths were interpreted using Cohen (1988) decision rules where $r$ values from 0.1 to 0.3 indicate weak correlation, 0.31 to 0.5 indicate moderate correlation strength and greater than 0.5 indicate a strong correlation between the variables. Correlation is statistically significant at 0.05 levels if $p$ values are 0.05 and are not statistically significant if $p$ values are more than 0.05 . Table 4.4 shows results of the correlation analysis.

Table 4.4 Correlation between Workforce Diversity and Employee Performance

\begin{tabular}{llrr}
\hline Variables & & Workforce Diversity & $\begin{array}{c}\text { Employee } \\
\text { Performance }\end{array}$ \\
\hline \multirow{2}{*}{ Workforce Diversity } & Pearson Correlation & 1 & $0.456^{* *}$ \\
& Sig. (2-tailed) & & 0.000 \\
& N & 93 & 93 \\
Employee Performance & Pearson Correlation & $0.456^{* *}$ & 1 \\
& Sig. (2-tailed) & 0.000 & 93 \\
& N & 93 & \\
\hline
\end{tabular}

**. Correlation is significant at the 0.01 level (2-tailed).

A correlation analysis was carried out on all the four variables of workforce diversity and employee performance and the results reveal that there is a statistically significant moderate positive association between workforce diversity and employee performance in public universities in Western Kenya, $r=0.456, p<0.001$, Confidence Level $=95 \%$ (2-tailed). This means that when workforce diversity improves, then employee performance also improves in public universities in Western Kenya. The result supports Hayles and Mendez (1997) research on the diversity directive which found out a strong correlation between good diversity practices and employee performance and therefore profits to firms. This is also supported by Alder (1997) who argues that good workforce diversity practices in the area of human resources are believed to enhance employee and organizational performance. Managing diversity therefore involves leveraging and using the cultural differences in people's skills, ideas and creativity to contribute to a common goal, and doing it in a way that gives the organization a competitive edge.

\section{Multiple Linear Regression Analysis results for all Variables}

The study aimed at establishing the overall effect of workforce diversity on employee performance of public universities in Western Kenya. The workforce diversity variables under review were; age diversity, gender diversity, ethnic diversity and education background diversity. The regression 
INTERNATIONAL JOURNAL OF ACADEMIC RESEARCH IN BUSINESS AND SOCIAL SCIENCES

Vol. 9, No. 7, July, 2019, E-ISSN: 2222-6990 @ 2019 HRMARS

analysis of the overall model without the moderating variable determined the significance of the relationship of the independent variable-Workforce Diversity on the dependent variable- Employee Performance. Results are presented in table 4.5.

Table 4.5 Multiple Linear Regression for the Performance Model (un-moderated)

\begin{tabular}{|c|c|c|c|c|c|c|c|c|}
\hline \multirow[t]{2}{*}{ Model } & \multicolumn{2}{|c|}{$\begin{array}{l}\text { Unstandardize } \\
\text { d Coefficients }\end{array}$} & \multirow[t]{2}{*}{$\mathrm{T}$} & \multirow[t]{2}{*}{ Sig. } & \multicolumn{2}{|c|}{$\begin{array}{c}95.0 \% \text { Confidence } \\
\text { Interval for B }\end{array}$} & \multicolumn{2}{|c|}{$\begin{array}{l}\text { Collinearity } \\
\text { Statistics }\end{array}$} \\
\hline & B & $\begin{array}{l}\text { Std. } \\
\text { Error }\end{array}$ & & & $\begin{array}{l}\text { Lower } \\
\text { Bound }\end{array}$ & $\begin{array}{l}\text { Upper } \\
\text { Bound }\end{array}$ & $\begin{array}{c}\text { Toleranc } \\
\mathrm{e}\end{array}$ & VIF \\
\hline (Constant) & 3.115 & 2.939 & 1.060 & 0.292 & -2.726 & 8.956 & & \\
\hline Age Diversity & 0.622 & 0.311 & 2.003 & 0.048 & 0.005 & 1.239 & 0.913 & 1.096 \\
\hline Gender Diversity & 0.204 & 0.091 & 2.230 & 0.028 & 0.022 & 0.386 & 0.709 & 1.410 \\
\hline Ethnic Diversity & 0.041 & 0.061 & 0.679 & 0.499 & -0.079 & 0.162 & 0.868 & 1.152 \\
\hline $\begin{array}{l}\text { Education } \\
\text { Background } \\
\text { Diversity }\end{array}$ & 0.192 & 0.086 & 2.225 & 0.029 & 0.021 & 0.364 & 0.631 & 1.584 \\
\hline
\end{tabular}

The model was as follows:

$\mathbf{Y}=3.115+0.622 \mathrm{X}_{1}+0.204 \mathrm{X}_{2}+0.041 \mathrm{X}_{3}+0.192 \mathrm{X}_{4}$

The multiple linear regression was carried out and the findings show that the regression coefficients are positive for each independent variable, and as such, in concurrence with the hypothesis that each individually positively influences employee performance. In addition, age diversity contributes most in enhancing employee performance $(\beta=0.622, p=0.048$, this is followed by gender diversity $(\beta=0.204$, $p=0.22)$, educational background diversity $(\beta=0.192, p=0.029)$. Ethnic diversity has the least contribution to employee performance $(\beta=0.041, p=0.449)$. These results are consistent with The results are in agreement with Ogbo, Ukpere and Kufordu (2014) study on the effect of workforce diversity on organizational performance of selected firms in Nigeria which indicate that employee diversity improves the quality of services provided to the customers. 
INTERNATIONAL JOURNAL OF ACADEMIC RESEARCH IN BUSINESS AND SOCIAL SCIENCES

Vol. 9, No. 7, July, 2019, E-ISSN: 2222-6990 C 2019 HRMARS

Model Summary

Table 4.6 Direct Effect Model

Model Summary

\begin{tabular}{|l|r|r|r|r|}
\hline Model & R & R Square & Adjusted R Square & \multicolumn{1}{c|}{$\begin{array}{c}\text { Std. Error of the } \\
\text { Estimate }\end{array}$} \\
\hline 1 & $0.839^{\mathrm{a}}$ & 0.704 & 0.698 & 3.82141 \\
\hline
\end{tabular}

a. Predictors: (Constant), Age Diversity, Gender Diversity, Ethnic Diversity and Education Background Diversity

The $R$ value is the correlation coefficient between the dependent variable and the independent variables. According to the Model Summary, the value of correlation coefficient $(R)$ of four independent variables (age diversity, gender diversity, ethnic diversity and education background diversity) with the dependent variable (employee performance) is 0.839 . Therefore, there is positive and high correlation between four independent variable and dependent variable. Besides that, Model Summary also indicates the coefficient of determination ( $R$ square). The findings showed that the independent variables: age diversity, gender diversity, ethnic diversity and education background diversity explained $70.4 \%\left(R^{2}=0.704\right)$ of the variance in the dependent variable, employee performance. However, it is still leaves $29.6(100 \%-70.4 \%)$ unexplained in this research. In other words, there are other additional variables that are important in explaining employee performance that have not been considered in this research.

\section{Conclusion}

The first conclusion of this study is that age diversity the most critical of all the variables and positively influences employee performance in public universities in Kenya. There is a statistically significant moderate positive association between age diversity and employee performance. Majority of the employees in public university are positive about age diversity initiatives and age difference does not cause conflict in this institutions. In addition, there is equal opportunities for training and development for employees in different age groups. However, public universities should strive to recognize younger employees in team success this is because majority of the team leaders are experienced and mature employees and much of the recognition for team success goes to them.

The second conclusion is that gender diversity positively influences employee performance in public universities in Kenya. There is a statistically significant moderate positive association between gender diversity and employee performance. Majority of the employees in public universities are positive about gender diversity practices and opportunities for growth and promotion exist for the female gender. However, these institutions should strive to increase representation of female employees in leadership positions in teams.

The third conclusion is that ethnic diversity positively influences employee performance in public universities in Kenya. There is a statistically significant positive association between ethnic diversity 
and employee performance. Majority of the employees in public universities are positive about ethnic diversity practices in their institutions and team leaders do not discriminate members based on ethnic background in public universities. However, out on all the four study independent variables multiple linear regression showed that ethnic diversity has the least contribution to employee performance and therefore these organizations should embrace ethnic diversity initiatives specifically on respects for employees' custom, culture and values.

The fourth conclusion is that education background diversity influences employee performance in public universities in Kenya. There is a statistically significant moderate positive association between education background diversity and employee performance and majority of the employees in public universities are positive about education background programs. Nevertheless, differences in education backgrounds do not cause conflict among employees in these institutions. However, universities being institutions of higher learning they employ staff with very high level knowledge and skills and the challenge is to organize their recruitment plan so that it considers education background of the employees especially for lower cadre jobs and entry level employees.

\section{Recommendations}

In view of the stated findings and conclusions, the study makes the following recommendations in order to improve the policy and practice in public Universities and other sectors. They are based on age diversity, gender diversity, ethnic diversity and education background diversity.

\section{Recommendations for Policy and Practice}

1. The first recommendation is that public universities should come up with motivation programs that recognize younger employees in team success this is because majority of the team leaders are experienced and mature employees and much of the recognition for team success goes to them.

2. Secondly, these institutions should strive to increase representation of female employees in leadership positions in teams not just as a fulfillment of affirmative policies but as positive gender diversity practice.

3. The third recommendation is that public universities should embrace ethnic diversity initiatives specifically on the concept of respects for employees' custom, culture and values.

4. Finally, universities being institutions of higher learning they employ staff with very high level knowledge and skills leading to a skewed workforce in relation to education level between academic, administrative staff and the support staff. Therefore, these institutions should organize their recruitment plan to accommodate education background of the employees especially for lower cadre jobs and entry level employees.

\section{References}

Adler, N. J. (2005). Cultural Synergy: Managing the Impact of Cultural Diversity. London: Sage Publications.

Adler, N. J. (1997). International Dimensions of Organizational Behavior. Cincinnati, Ohio: SouthWestern College Publishing. 
INTERNATIONAL JOURNAL OF ACADEMIC RESEARCH IN BUSINESS AND SOCIAL SCIENCES

Vol. 9, No. 7, July, 2019, E-ISSN: 2222-6990 @ 2019 HRMARS

Alserhan, B. A., Forstenlechner, I., and Al-Nakeeb, A. (2010). Employees' attitudes towards diversity in a nonwestern context. Employee Relations Journal. Vol. 32, No. 1. Emerald Group Publishing Limited.

Berry, L. M. (2010). Examining Turnover Intent: Examining the Effect of Employee Engagement, Compensation Fairness, Job Satisfaction and Age: PhD Thesis. Tennessee University. Executive Pay and Firm Performance: Methodological.

Carrel, M. R. (2006). Defining Workforce Diversity Programs and Practices in Organizations: A Longitudinal Study. Labor Law Journal. Spring, 2006.

Cohen, J. (1988). Statistical power analysis for the behavioral sciences (2nd edition). New Jersey State: Lawrence Erlbaum.

Cox, T. (2001).Creating the Multicultural Organization: A Strategy for Capturing the Power of Diversity, San Francisco: Jossey-Bass.

Ellis, C., Sonnenfield, J. A. (1993). Diverse Approaches to Managing Diversity. Human Resource Management Journal, Vol. 33 No.1. Emerald Publications.

Erasmus, L. (2007). The Management of Workforce Diversity and the Implications for Leadership at Financial Asset Services. Business Management, University of Johannesburg.

Gilbert, J. A., Stead, B. A and Ivancevich, J. M (1999). 'Diversity Management: A New Paradigm'. Journal of Business Ethics. No 21. Netherlands: Kinutt Academic Publishers.

Gordon, J. (1995). Different from What? Diversity as a Performance Issue. Training, Vol.32, 5, 25 33.

Hall, D. T., Parker, A. P. (1993). The role of workplace flexibility in managing diversity. Organizational Dynamics Journal. Vol. 22, No.1.

Hayles, R., Mendez, R. A. (1997). The Diversity Directive. New York: McGraw-Hill.

Jehn, K. A. (1999). Diversity, Conflict, and Team Performance: Summary of Program of Research. Performance Improvement Quarterly, 12(1), 6-19.

Kochan, T., Bezrukova, K., Ely, R., Jackson, S., Joshi, A., Jehn, K., Leonard, J., Levine, D., \& Thomas, D. (2003). The effects of diversity on business performance: Report of the diversity research network. Human Resource Management. 42. 3-21. 10.1002/hrm.10061.

Kothari, C. R. (2009). Research Methodology: Methods and Techniques. New Delhi. New Age International Publishers.

Loden, M., \& Rosener, J.B. (1991).Workforce America! Managing Employee Diversity as a Vital Resource. Burr Ridge, IL: Irwin.

Magoshi, E. \& Chang, E. (2009). Diversity management and the effects on employees' organizational commitment: Evidence from Japan and Korea. Journal of World Business, 44. 31-40. 10.1016/j.jwb.2008.03.018.

Mellenbergh, G. J. (2008). Tests and questionnaires: Construction and administration. In H. J. Adèr \& G. J. Mellenbergh (Eds.) (with contributions by D. J. Hand), Advising on research methods: $A$ consultant's companion (pp. 211-234). Huizen, The Netherlands: Johannes van Kessel Publishing.

Mugenda, O. M. \& Mugenda, A. G. (2003). Research Quantitative and Qualitative Approaches. $2^{\text {nd }}$. Rev. Ed. Nairobi: Act press. 
INTERNATIONAL JOURNAL OF ACADEMIC RESEARCH IN BUSINESS AND SOCIAL SCIENCES

Vol. 9, No. 7, July, 2019, E-ISSN: 2222-6990 ¿ 2019 HRMARS

O’Flynn, J., Ricciotti, A., Nicholas, S., Lau, K., Sammarino, A., Fisher, N., (2001). The theory of Diversity and Group Performance: Australian Centre for International business, 1-54.

Ogbo, A. I., Kufordu, A. A., \& Ukpere, W. I. (2014). The Effect of Workforce Diversity on Organizational Performance of Selected Firms in Nigeria. Mediterranean Journal of Social Sciences, 5(10), 231-236.

Richard, O. C., Kirby, S. L., \& Chadwick, K. (2013). The impact of racial and gender diversity in management on financial performance: How participative strategy making features can unleash a diversity advantage. The International Journal of Human Resource Management, 24(13), 25712582.

Sang, K. (2010). Outsourcing in Kenyan Universities. An Examination of Challenges and Opportunities. International Journal of Business and Social Science, 1, 204-212.

Sekaran, U. (2008). Research Methods for Business. A skill Building Approach., New York: John Willey \& Sons, Inc.

Tajfel, H. (1978). The Achievement of Group Differentiation: differentiations Between Social Groups. London, England: Academic Press.

Thatcher, S. (1999). The Contextual Importance of Diversity: The Impact of Relational Demography and Team Diversity on Individual Performance and Satisfaction. Performance Improvement Quarterly, 12(1), 97-112.

Turner, J. C. (1982). Towards a Cognitive Redefinition of Social Group. Cambridge, England: Cambridge University Press. 